\title{
Organizational Factors Affecting Employee Innovative Behavior
}

\author{
Kabasheva I.A. a \\ Rudaleva I.A. ${ }^{b}$ \\ Bulnina I.S.c \\ Askhatova L.I. ${ }^{d}$ \\ a bc d Kazan Federal University, Institute of Management, Economics and Finance, Kazan, 420008, Russia
}

\section{Doi:10.5901/mjss.2015.v6n1s3p435}

\section{Abstract}

The research analyzed employers innovative behavior of the organization and importance of influencing factors on it. As research methods were chosen method of structured interrogation, the method of pairwise comparisons, expert evaluation and correlation and regression analysis. The research results were gender difference in innovative employer behavior: more favorable innovation perception in woman - 57\%, in men - 43\%, the majority of an active reformers (willing, able to work and active), found among female workers - 65\%, 50\% among male. The research results confirm necessities of the system formation of material and moral stimulation of the staff to take part in creation and realization of the innovation. For the company's management innovative oriented enterprise is recommended on the selection stage and hiring identify staff with appropriate type «active reformer» and "passive reformer».

Keywords: innovations, innovative behavior, innovative readiness, factors of innovative behavior, model, staff, organization

\section{Introduction}

Currently, the task of searching mechanisms and tools of employee potential activation in generating new ideas and practical realization of innovations is becoming more relevant. The employees' readiness to implement innovations is dictated by their perception of the innovation process and the innovation situation. It defines their innovation susceptibility.

In order to understand innovative behavior of employees it is important to understand difficulties and obstacles which innovating employees meet, the causes of psychological barriers, etc. In the process of innovation, some psychological barriers can be overcome, while others, on the contrary, increase, which in the long term leads to the emergence and spread of conflicts in the work environment.

The relevance of this topic raises great interest among representatives of the scientific world who explore various sides and relationships of the innovative behavior of employees with other aspects of their social and work life.

Thus, a group of authors, such as De Jong J.P.J., Den Hartog D.N., studied the impact of the leadership behavior of managers who are responsible for the innovation strategies in organizations on the innovative behavior of employees. The results indicate the importance of the analyzed relationships. Leaders influence employees' innovative behavior both through their deliberate actions aiming to stimulate idea generation and application as well as by their more general, daily behavior. [1]

A similar study of the complex and contradictory relations of the leadership and innovation receptivity of employees was undertaken by Rosing K., Frese M., Bausch A. In order to achieve this aim they suggested the ambidexterity theory of leadership for innovation that specifies two complementary sets of leadership behavior that foster exploration and exploitation in individuals and teams - opening and closing leader behaviors, respectively. The ambidexterity theory relationships the authors termed as mirror symmetry leadership, because it utilizes opening and closing leader behaviors and switches between them to deal with the ever-changing requirements of the innovation process. [2]

In the study, the authors convincingly argue that the transfer of innovative knowledge in the organization is significantly affected by the combination of formal and informal interactions of employees. The result of that joint action is the formation of complex networks of interaction between employees of all levels, which enhance the diffusion of innovations in the organization. "The exact overlap between formal as well as informal contacts between individuals, forming multiplex or what we call rich ties because of their contribution, especially drives the transfer of new, innovative 
knowledge in a firm. Studying two cases in very different settings suggests these rich ties have a particularly strong effect on knowledge transfer in an organization, even when controlling for the strength of ties». [3]

The impact on the innovative behavior of employees (30 high-tech companies) of different types was studied by a group of scientists, such as H.-T. Chang, H.-M. Hsu, J.-W. Liou, C.-T. Tsai. They came to the following conclusions: firstly, work engagement fully mediated the negative relationship between transactional contracts and innovative behavior; in addition, it also fully mediated the positive relationship between relational contracts and innovative behavior; secondly, job resources attenuated the former and strengthened the latter mediating effects. [4]

The research of D. De Clercq, D. Dimov, I. Belausteguigoitia was dedicated to analyzing the relationship of innovative susceptibility of employees and unfavorable working conditions. In their study, they prove that the adverse working conditions, namely, work overload significantly impede the receptivity of employees to innovations. At the same time organizations which seek to adopt innovative ideas in the presence of adverse work conditions thus should create relational conduits that can mitigate the associated stress. [5]

Similar results in the study of innovative behavior in top managers in the field of public health also showed that the effect of burnout and anxiety in the workplace is significantly connected with low distributive and procedural fairness. [6]

A significant number of studies in the field of innovation receptivity of employees is based on the fact that producing creative ideas does not necessarily lead to their practical implementation. Hence, researchers try to identify the conditions, opportunities and characteristics conducive to the implementation of innovations. In the work of M. Baer, the relationship between the creation and realization of innovative ideas is regulated, first of all, by the system of employee motivation and their capability for network interactions within the organization. The study showed that the employees were able to improve the realization of their ideas when they expected positive results from the efforts they had taken to implement them. And also when they were skilled networkers or had developed a set of strong "buy-in" relationships. [7]

In the context of our research, economists have a great interest as it relates to their work. K. Birdi, D. Leach and W. Magadley revealed the close connection of employee innovative behavior (the generation of new knowledge, creativity, operational skills and examination of employees' activities, the patent, motivation, etc.) and practical implementation of innovations. Looking at design engineers in a multinational engineering company, they obtained interesting results. Such components of employee innovative behavior as operational skills, motivation of innovations and the examination of activities demonstrated the most significant relationship to the practical implementation of innovative ideas. However, creativity and relevant skills of employees, as well as institutional innovation support, were positively associated with the indicators of generating innovative ideas, but not with the practical implementation of innovations. [8]

A similar study was undertaken by R. M. Stock who analyzed the ability of employees to generate innovative solutions and practically implement them in their organizations. Highlighting the interconnection of the innovative behavior of employees with their passion at work, the author focuses on the negative psychological states that occur in three main forms: crisis of meaning in relation to work, monotony and the crisis of opportunities for professional and career growth. The research results confirm the impact of these characteristics, although to a different extent, on the innovative behavior of employees. So, the crisis of meaning at work and the crisis of professional and career growth are serious obstacles to innovation receptivity of employees, but monotony and boredom in the workplace do not affect it. [9]

Another group of scientists have analyzed the tendency of employees to innovate by focusing their attention on specific professional requirements, and the respective competencies, such as alertness to new opportunities, ability to present products, ideas or reports, ability to mobilize the capacities of others, ability to come up with new ideas and solutions, and ability to use computers and the Internet, and others. The results show a significant effect of the relationship between the process of developing the competencies of employees and their innovative behavior in the work environment. [10]

Concerning the socio-psychological attitudes to innovation, the ratio of at least three components - readiness for innovation which is the motivational component; readiness for the new conditions of life (knowledge, skills, experience) which is the cognitive component; and real activity (actions, behavior) which is the behavioral component - should be taken into consideration. A. Zhuravlev classifies socio-economic personality types into the following categories depending on one's attitude to innovation: «active reformers» (those willing and capable to work and active); «the passive reformers» (willing and capable to work, but not active); «the passive opponents» (not willing, nor capable to work and not active; «the active opponents» (not willing and not capable to work and actively against any changes). [11] The aim of our study is to assess the determinants of innovative behavior of employees operating in the field of road construction.

As methods of research, the following were selected: the method of structured survey, the method of paired comparisons, observation (structured and unstructured), a structured interview, the method of expert evaluation. Statistical analysis of the empirical research data was conducted with the help of factor analysis and correlation and regression analysis, using the program package GRETL. 
Our study of employees' attitude to innovations was based on the following question: "Are you ready to participate in introduction of innovations in your organization?" Two possible answers were offered to choose: "yes" and "no".

Based on the processing and analysis of the questionnaires one can note some more favorable perception of innovation by women - $57 \%$, rather than by men - $43 \%$.

Also the employees were suggested to answer questions in order to determine their socio-economic personality type (according to the method proposed by A. Zhuravlev). In the end, we obtained the following results, shown in Pic 1. Active reformers were detected more among female employees (active, willing and able to work) - 65\%, while among men there were $50 \%$ respondents who met such characteristics.

However, it turned out that among men there were significantly more passive reformers (those willing and able to work, but not active), over $27 \%$, while only $9 \%$ among women. Males potentially have more opportunities for innovations, but they are passive in using them. By contrast, women, with less resource opportunities, demonstrate more innovative activity.

With regard to the proportion of passive innovation opponents (those not willing, not able to work and not active) and active innovation opponents (those not willing, not able to work, and opposing changes), they were distributed as follows: $15 \%$ and $8 \%$ of men, and $23 \%$ and $3 \%$ of women.

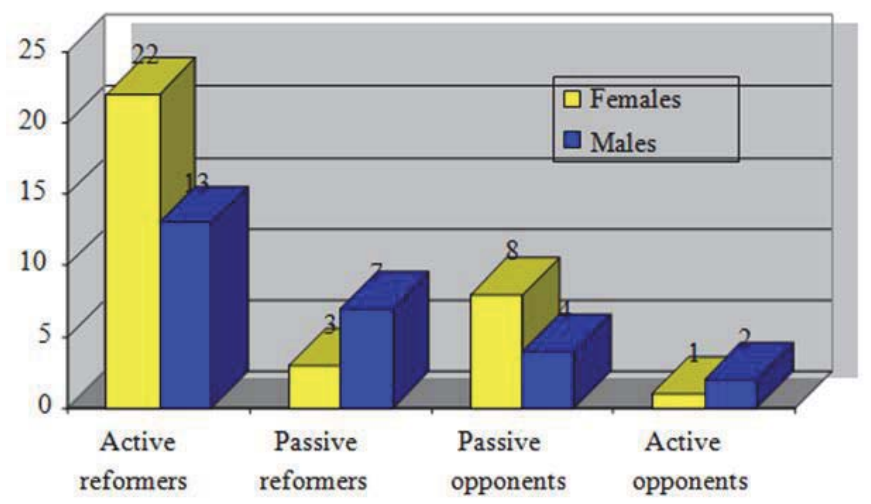

Pic 1. The analysis of employees in the context of socio-economic personality type

Analysis of the age structure of employees showed overwhelming positive perception of innovation by men, aged 41-50 years (35\%), and women, aged $31-40$ years (42\%).

The majority of workers, employees, and executives of the analyzed organization have significant experience of practical introduction of innovations. At the same time their readiness to start implementation of innovative projects and technologies is estimated very high: $73 \%$ of women ( 25 out of 34 people) and $65 \%$ of men (17 out of 26 people).

The most active in the innovation process are the employees with higher education, among which the distribution between men and women was $61 \%$ and $67 \%$, respectively. This can give a start to changes of work organization in the company.

The regression analysis made it possible to build the following model of paired regression. As the dependent variable $Y$ were used responses to the question "Are you ready to take part in the introduction of innovations (innovation) in your organization?" A socio-economic personality type, participation in seminars (conferences), participation in advanced training programs and internships, suggesting for improvement of organization's work, experience of practical implementation of those suggestions in professional activity, a system of motivation of innovative activity in the company were consistently considered as determinants of innovation propensity. It was found out that among the most significant determining factors were the motivation system of innovations in the company $\left({ }^{x_{1}}\right)$ and a socio-economic personality type $\left(x_{2}\right)$. As a result, the following model was obtained (Table 1).

Table 1. Model parameters

\begin{tabular}{|c|c|c|c|c|c|}
\hline & Coefficient & Standard error & t-statistics & P-value & \\
\hline const & 0.927538 & 0.143362 & 1.4196 & 0.16116 & \\
\hline$x_{1}$ & 0.260919 & 0.125138 & 2.0851 & 0.04155 & $* * *$ \\
\hline$x_{2}$ & 0.31426 & 0.154501 & 2.0340 & 0.04661 & $* * *$ \\
\hline
\end{tabular}


Table 2. Qualitative characteristics of the model

\begin{tabular}{|c|c|}
\hline Indicators & Value \\
\hline R-squared & 0.926916 \\
\hline $\mathrm{F}(1.3)$ & 38.04856 \\
\hline Standard dispersion of dependant variable & 0.242758 \\
\hline Standard model error & 0.07678 \\
\hline Corrected R-squared & 0.902554 \\
\hline P-value (F) & 0.008577 \\
\hline
\end{tabular}

The constructed model is qualitative, since the coefficient of determination is equal to 0.926916 . This suggests that the factors considered in the model explain to $92,69 \%$ the dependence of the propensity to innovation formation on a socioeconomic personality type and the existing system of motivation of innovative activities in the organization. Less than $7 \%$ are the unrecorded factors in the model.

According to Fisher's a model is significant if Fobt > Fcrit.

The $p$-value in the model equals to 0.008577 which indicates its quality.

The degree of reliability is determined by comparing the standard errors and the regression coefficient. The standard error of the regression model is 0.07678 , which is less than the regression coefficient ( $R$-squared $=0.926916$ ). If the standard error value is larger than the regression coefficient, than this coefficient is not significant. Thus, by this criterion, the model is qualitative.

Based on what was said above, the regression equation will look as follows:

$Y=0.9275+0.2609 \cdot x_{1}+0.3143 \cdot x_{2}(1)$

The system of motivation of innovative activities, as well as a socio-economic personality type has the greatest influence on the level of innovative activity of employees in the organization.

Thus, the results of the study confirmed the necessity of formation of the system of material and moral incentives for employees to participate in the implementation of innovative projects. To the management of an enterprise of innovative orientation it is recommended in the stage of recruitment and employment to reveal employees corresponding to the types "active reformer" and "passive reformer".

\section{References}

De Jong J.P.J., Den Hartog D.N. (2007) How leaders influence employees' innovative behavior. European Journal of Innovation Management 10 (1), pp. 41-64

Rosing K., Frese M., Bausch A. (2011) Explaining the heterogeneity of the leadership-innovation relationship: Ambidextrous leadership. Leadership Quarterly 22 (5), pp.956-974

Aalbers R., Dolfsma W., Koppius O. (2014) Rich Ties and Innovative Knowledge Transfer within a Firm. British Journal of Management Volume 25, Issue 4, pp.833-848

Chang H.-T., Hsu H.-M., Liou J.-W., Tsai C.-T. (2013) Psychological contracts and innovative behavior: a moderated path analysis of work engagement and job resources. Journal of Applied Social Psychology Volume 43, Issue 10, pp.2120-2135

De Clercq D., Dimov D., Belausteguigoitia I. (2014) Perceptions of Adverse Work Conditions and Innovative Behavior: The Buffering Roles of Relational Resources. Entrepreneurship Theory and Practice. Early View (Online Version of Record published before inclusion in an issue)

Janssen O. (2004) How fairness perceptions make innovative behavior more or less stressful. Journal of Organizational Behavior, Volume 25, Issue 2, pp.201-215

Baer M. (2012) Putting creativity to work: The implementation of creative ideas in organizations. Academy of Management Journal 55 (5), pp.1102-1119

Panasyuk, M.V., Dzasaeva, R.D., Shaidullin, R.N., Anopchenko, T.Y. Problems of modernization of the health economics in the russian regions // World Applied Sciences Journal, 27(13), 2013, 154-158.

Isaeva, T.N., Safiullin, L.N., Bagautdinova, N.G., Shaidullin, R.N. Aspects of a multi-level study of competitive performance of objects and subjects of economic management // World Applied Sciences Journal, 27(13), 2013, 116-119.

Birdi K., Leach D., Magadley W. (2014) The Relationship of Individual Capabilities and Environmental Support with Different Facets of Designers' Innovative Behavior. Journal of Product Innovation Management. Early View (Online Version of Record published before inclusion in an issue) http://onlinelibrary.wiley.com/journal/10.1111/(issn)1540-5885/earlyview

Stock R.M. (2014) Is Boreout a Threat to Frontline Employees' Innovative Work Behavior? Journal of Product Innovation Management. Early View (Online Version of Record published before inclusion in an issue) http://onlinelibrary.wiley.com/journal/10.1111/ (issn)1540-5885/earlyview

Vila L.E., Pérez P.J., Coll-Serrano V. (2014) Innovation at the workplace: Do professional competencies matter? Journal of Business 
Research 67 (5), pp. 752-757

Social Psychology. / Ed. Zhuravlev A.L. - M., 2002. - 351p.

Safiullin L.N., Fatkhiev A.M., Safiullina L.M. Projected trends and problems of education. Life Science Journal 2014; 11 (6s): $384-387$. 